\title{
Cyclic gas exchange in the giant burrowing cockroach, Macropanesthia rhinoceros: Effect of oxygen tension and temperature
}

\author{
James D. Woodman ${ }^{\mathrm{a}, \mathrm{b}, *}$, Paul D. Cooper ${ }^{\mathrm{a}}$, Victoria S. Haritos ${ }^{\mathrm{b}}$ \\ ${ }^{\mathrm{a}}$ CSIRO Entomology, GPO Box 1700, Canberra ACT 2601, Australia \\ ${ }^{\mathrm{b}}$ School of Botany and Zoology, Australian National University, Canberra ACT 0200, Australia
}

Received 4 December 2006; received in revised form 29 January 2007; accepted 29 January 2007

\begin{abstract}
The giant burrowing cockroach, Macropanesthia rhinoceros, is endemic to north-eastern Australia and excavates a permanent burrow up to $1 \mathrm{~m}$ deep into soil. Using flow-through respirometry, we investigated gas exchange and water loss at three different oxygen tensions $\left(21 \%, 10 \%\right.$ and $2 \%$ at $\left.20^{\circ} \mathrm{C}\right)$ and temperatures $\left(10,20\right.$ and $30{ }^{\circ} \mathrm{C}$ at $21 \%$ oxygen). M. rhinoceros employ cyclic gas exchange (CGE)

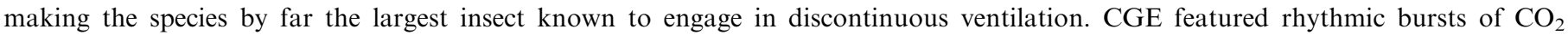
dispersed among inter-burst periods of reduced output. CGE was most commonly observed at $20^{\circ} \mathrm{C}$ and degraded at $<10 \%$ oxygen. Mild hypoxia (10\% oxygen) resulted in a lengthening of the burst period by approximately two-fold; this result is complementary to oxygen consumption data that suggests that the burst period is important in oxygen uptake. When exposed to severe hypoxia ( $2 \%$ oxygen), CGE was degraded to a more erratic continuous pattern. Also, during severe hypoxia, total water loss increased significantly, although $\mathrm{CO}_{2}$ release was maintained at the same level as in $21 \%$ oxygen. During CGE, an increase in temperature from 10 to $20{ }^{\circ} \mathrm{C}$ caused both water loss and $\mathrm{CO}_{2}$ output to double; from 20 to $30^{\circ} \mathrm{C}, \mathrm{CO}_{2}$ output again doubled but water loss increased by only $31 \%$.
\end{abstract}

(C) 2007 Published by Elsevier Ltd.

Keywords: Hypoxia; Respirometry; Insect; Underground; Giant burrowing cockroach

\section{Introduction}

Insects typically feature very efficient gas exchange that is flexible and able to support greatly increased respiration rates associated with periodic activity (Reinhold, 1999). Insects employ a range of ventilation types including continuous gas exchange, cyclic gas exchange (CGE) and discontinuous gas exchange (DGE) with larger insects in particular often relying on ventilatory movements to assist the exchange of oxygen and $\mathrm{CO}_{2}$ (Slama, 1999; Chown and Nicholson, 2004). DGE represents the most discretely partitioned form of discontinuous ventilation and has been observed for a number of terrestrial tracheate arthropods when at rest (Chown et al., 2006). DGE is divided into a closed phase where carbon dioxide release is negligible, a flutter phase where the spiracles are rapidly opened and

\footnotetext{
*Corresponding author. School of Botany and Zoology, Australian National University, Canberra ACT 0200, Australia.

E-mail address: james.woodman@csiro.au (J.D. Woodman).
}

closed with little $\mathrm{CO}_{2}$ release and an open phase which results in bulk discharge of accumulated carbon dioxide (Reviews: Lighton, 1996; Chown et al., 2006). Recently, attention has been focused on DGE as a distinct form of CGE, which describes similar rhythmic bursts of $\mathrm{CO}_{2}$ interspersed among inter-burst periods during which $\mathrm{CO}_{2}$ release never decreases to negligible levels (Gray and Bradley, 2006). Despite this, our understanding of how and why these patterns are employed remains limited. The question of why an insect exhibits DGE or CGE at rest is curious and whilst a number of hypotheses have been proposed, we still lack any definitive answer (Chown et al., 2006). Two prominent hypotheses have suggested that DGE or CGE may assist in maintaining efficient gas exchange in underground burrows (i.e. low oxygen conditions) and/or minimise respiratory water loss.

As insects become larger it has been hypothesised that gas exchange becomes more challenging due to diffusive limitations associated with increased tracheal system length (Graham et al., 1995; Dudley, 1998). During periods of 
higher atmospheric oxygen levels (i.e. exceeding the present $21 \%$ ), such as that from the Palaeozoic, insects were freed of this limitation which supported insect gigantism. For the largest of the extant insects, tolerance to hypoxic conditions may be limited due to reduced safety margins. To overcome this, some animals may have evolved greater tracheal diameters and more actively engage in ventilation (Greenlee and Harrison, 2004), or alternatively, tolerance to lowered oxygen may remain more marginal.

Large insects that live within confined habitat such as that experienced in underground burrows may face very different conditions to those experienced by an aboveground species. Notably, underground burrows may be subjected to decreased oxygen availability and/or elevated carbon dioxide tension (Anderson and Ultsch, 1987; Hoback and Stanley, 2001). Gas exchange in animals exposed to such atmospheres must therefore be flexible and capable of supporting metabolic requirements under a range of conditions that may deviate from normoxia.

Endemic to tropical and sub-tropical regions in northeastern Australia, Macropanesthia rhinoceros is a long-lived insect that excavates a burrow up to $1 \mathrm{~m}$ deep into soil. Considering M. rhinoceros spends extended periods of time underground, it is reasonable to assume that high amounts of organic material, poor ventilation, soil microbial activity and respiration may result in hypoxic conditions (Anderson and Ultsch, 1987). The effects that hypoxic conditions may impose on gas exchange for such a large species is therefore of substantial interest. At an average adult mass of $26 \mathrm{~g}, M$. rhinoceros is by far the largest insect whose means of gas exchange has been investigated. We were interested in three questions pertaining to their size and habitat: (a) what pattern of gas exchange do these animals employ? (b) How might low oxygen levels influence the normal respiratory pattern? (c) How does temperature affect total $\mathrm{CO}_{2}$ output and evaporative water loss?

\section{Methods}

\subsection{Study species}

M. rhinoceros is the largest species in a group of soil burrowing cockroaches (Blattodea: Blaberidae: Geoscaphinae) endemic to Australia and upon maturity attain a body length of approximately $80 \mathrm{~mm}$. They live in permanent underground burrows which extend up to $1 \mathrm{~m}$ in length and feed on dry leaf litter (Day, 1950; Rugg and Rose, 1991). Individuals are typically solitary however young nymphs will remain with the mother for some months and adult males may co-habit with late-instar female nymphs. They are all wingless with populations separated by unsuitable soil types or water barriers (Brown et al., 2000).

Study animals were obtained from The Insect Farm in north-eastern Australia. Each mature adult individual was housed in a plastic container $(21 \times 27 \times 12 \mathrm{~cm})$ which was prepared with at least $5 \mathrm{~cm}$ of washed river sand. Each container was supplied with ample dry eucalypt leaf litter as a food source and water saturated cotton wool for drinking. The animals were kept at $20 \pm 2{ }^{\circ} \mathrm{C}$ under a $12: 12 \mathrm{~h}$ light/dark regime and each container featured a number of holes on the top to provide ventilation.

\subsection{Respirometry}

Standard patterns of respiration were recorded at $21 \%$ oxygen and $20^{\circ} \mathrm{C}$. For measuring the effects of oxygen concentration on gas exchange, reduced oxygen tensions of $10 \%$ and $2 \%$ were used. The effects of temperature were recorded at $21 \%$ oxygen at 10,20 and $30{ }^{\circ} \mathrm{C}$. Adult male M. rhinoceros were used for all trials and for each experiment data was collected over a $5 \mathrm{~h}$ period by flowthrough respirometry using a Licor $7100 \quad \mathrm{CO}_{2} / \mathrm{H}_{2} \mathrm{O}$ differential infrared gas analyzer calibration checked before use (Li-Cor, Lincoln, USA). An inline oxygen analyzer (Model S-3A/II, AEI Technologies, USA) was used for simultaneous measurement of oxygen for a small number of trials at $21 \%$ oxygen and $20^{\circ} \mathrm{C}$.

A custom-built chamber was used that consisted of clear, cylindrical Perspex tubing (internal dimensions: radius $25 \mathrm{~mm}$, length $72 \mathrm{~mm}$, volume $141.4 \mathrm{~cm}^{3}$ ) and end caps with gas fittings internally secured with rubber rings. A single chamber loaded with a live organism was introduced into the gas line (using Bev-a-line IV tubing) within a darkened incubator that controlled temperature $\pm 0.1^{\circ} \mathrm{C}$ (Binder KB-series incubator; Binder, Germany). Gas was drawn through the system by an Edwards E2M-1.5 high-vacuum pump (BOC-Edwards, BOC group Inc.). The experiments were run with a gas of known composition passing through the chamber at a rate of either 200 or $350 \mathrm{~mL} \mathrm{~min}^{-1}$. The higher flow rate was used for the $2 \%$ and $10 \%$ oxygen trials to improve resolution for discrimination between phases. The gas mixtures of designated oxygen concentration were made by diluting dry, $\mathrm{CO}_{2}$-free air with high purity $\mathrm{N}_{2}$ as required. The ratio of each gas used to achieve a desired mixture was controlled by a Brooks 5878 massflow controller with three Brooks 5850TR mass-flow meters (one each for vacuum, air and $\mathrm{N}_{2}$ ) which were calibrated using a digital flow meter before use at 0-500 $\mathrm{mL} / \mathrm{min}^{-1}$ (Brooks Instruments, Hatfield, USA).

\subsection{Treatments}

For trials at 10,20 or $30^{\circ} \mathrm{C}$, oxygen tension was kept constant at $21 \%$. For trials at $2 \%, 10 \%$ or $21 \%$ oxygen, temperature was kept constant at $20^{\circ} \mathrm{C}$. For each treatment six individuals were used each held for approximately $24 \mathrm{~h}$ before each trial without food. Each animal was weighed and then allowed to acclimate for $30 \mathrm{~min}$ to the experimental temperature at normoxia. Upon being introduced into the chamber, the animal was immediately exposed to the experimental gas mixture. Specimens were visually monitored during a trial and any movement was noted either from direct observation or movement related 
$\mathrm{CO}_{2}$ peaks which were clearly identifiable. Individuals were used repeatedly at each different treatment but were rested for a period of at least $48 \mathrm{~h}$ between trials. Raw data from the gas analyzers were logged on a personal computer using Licor LI7000 data acquisition software (Version 1.0.1).

\subsection{Data handling}

The data from each trial were imported into Microsoft Excel. CGE cycles were selected for analysis $(n=2-10$ per animal) from each trial such that periods of activity and transition between continuous gas exchange and CGE were discarded. A CGE cycle had to exhibit an inter-burst period whereby low $\mathrm{CO}_{2}$ output was maintained, followed by a clearly defined $\mathrm{CO}_{2}$ burst phase. Despite the use of a higher flow rate, the selection of reliable CGE cycles was more difficult at $2 \%$ oxygen due to gas exchange becoming predominantly continuous.

Data was analysed using generalised linear models modified for repeated measures (JMP statistical software (version 4.0) (SAS Institute Inc., USA)). Individual animals were treated as random variables and mass as a covariate due to variation between treatments. Insect mass, water loss rates and $\mathrm{CO}_{2}$ output rates corrected to STP were log transformed before analyses. Proportions (\% time at rest; $\%$ time in CGE during rest) were arcsin transformed before analysis. Temperature and oxygen concentration were treated as nominal factors in the model, each with three levels $\left(10,20\right.$ and $30{ }^{\circ} \mathrm{C}$ and $2 \%, 10 \%$ and $21 \%$ oxygen).

\section{Results}

Typical gas exchange patterns from immobile $M$. rhinoceros at $20{ }^{\circ} \mathrm{C}$ in $21 \%$ oxygen, moderate hypoxia ( $10 \%$ oxygen) and severe hypoxia (2\% oxygen) are shown in Fig. 1. CGE in its most typical state was most commonly observed at $20{ }^{\circ} \mathrm{C}$ whilst an immobile individual was exposed to either $21 \%$ oxygen or moderate hypoxia $(10 \%$ oxygen). CGE patterns similar to that at $20{ }^{\circ} \mathrm{C}$ were also observed at 10 and $30^{\circ} \mathrm{C}$ however there were fewer complete cycles and increased variation. Total $\mathrm{CO}_{2}$ release during CGE increased with temperature $(F=21.6$, d.f. $=2, p<0.001)$ whereby it doubled each increase of $10{ }^{\circ} \mathrm{C}$. Each cycle featured a clear burst phase with some ventilatory saw-toothing presumably due to either rapid spiracular opening and closing or active ventilation during the burst phase (Fig. 1a, b). A distinct closed phase as part of the inter-burst period was not observed.

\subsection{Effects of oxygen and temperature on movement and time spent performing CGE}

The proportion of time animals spent immobile did not vary among treatments (oxygen, $F=0.38$, d.f. $=2$, $p=0.69$; temperature, $F=1.66$, d.f. $=2, p=0.22$ ), however treatments did affect the proportion of time that animals exhibited CGE (oxygen, $F=6.22$, d.f. $=2$, $p=0.01 ;$ temperature, $F=6.62, \quad$ d.f. $=2, \quad p=0.008$ ). Proportion of time spent immobile whilst exhibiting CGE decreased at $10 \%$ and $2 \%$ oxygen compared to $21 \%$ as well as at 10 and $30^{\circ} \mathrm{C}$ compared with $20^{\circ} \mathrm{C}$.

\subsection{Effects of oxygen tension on CGE}

Oxygen tension had no significant effect on the total $\mathrm{CO}_{2}$ output rate during CGE $(F=0.17$, d.f. $=2, p=0.85)$ as shown by consistent $\mathrm{CO}_{2}$ output rates regardless of the treatment (Table 1). Fig. 1b-d shows how gas exchange responded to decreased oxygen tension. The CGE pattern is maintained at $10 \%$ oxygen before becoming less cyclic and increasingly erratic at $2 \%$. It was not possible to present phase specific data for CGE at 2\% oxygen, however CGE degradation was characterised by greater $\mathrm{CO}_{2}$ output during a lengthened inter-burst period. Bursts become less frequent and less clearly differentiated from the greater inter-burst $\mathrm{CO}_{2}$ emission rates.

\subsection{Oxygen uptake during $C G E$}

Fig. 2 shows that oxygen consumption simultaneously peaked with $\mathrm{CO}_{2}$ bursts at normoxia and $20^{\circ} \mathrm{C}$ in comparison with the consistently low uptake during the inter-burst period. Although results are limited by a small number of useable traces $(n=4)$ and the relatively low sensitivity of the oxygen analyzer, it is clear that oxygen uptake is maximised during the burst period. At $10 \%$ oxygen, burst phase duration was nearly double that at $21 \%$ oxygen (Table 1 ).

\subsection{Water loss during $C G E$}

Water loss increased significantly as oxygen tension decreased $(F=4.32$, d.f. $=2, p=0.032)$ whereby the most dramatic difference was a $56 \%$ increase from $10 \%$ to $2 \%$ oxygen (Table 1). The rate of water loss also increased in response to temperature $(F=26.8$, d.f. $=2, p<0.001)$, doubling from 10 to $20^{\circ} \mathrm{C}$ and increasing by $31 \%$ from 20 to $30^{\circ} \mathrm{C}$ (Table 2). Total water loss rates remained approximately constant during $\mathrm{CO}_{2}$ burst and inter-burst periods at both normoxia and $10 \%$ oxygen at $20^{\circ} \mathrm{C}$ (Fig. 1a, b).

\section{Discussion}

The common respiration pattern of $M$. rhinoceros when immobile is CGE whereby a periodic $\mathrm{CO}_{2}$ release burst is followed by an inter-burst period of reduced $\mathrm{CO}_{2}$ output (Fig. 1). During the inter-burst periods, $\mathrm{CO}_{2}$ release did not fall to near zero. During CGE at $20^{\circ} \mathrm{C}$ and normoxia, $\mathrm{CO}_{2}$ bursts typically lasted $6.1 \mathrm{~min}$ and were separated by an inter-burst period of approximately $10 \mathrm{~min}$. Comparison of phase durations with other species is partially confounded by a lack of data for any other insect of similar size; nonetheless, the inter-burst period appears to represent a 

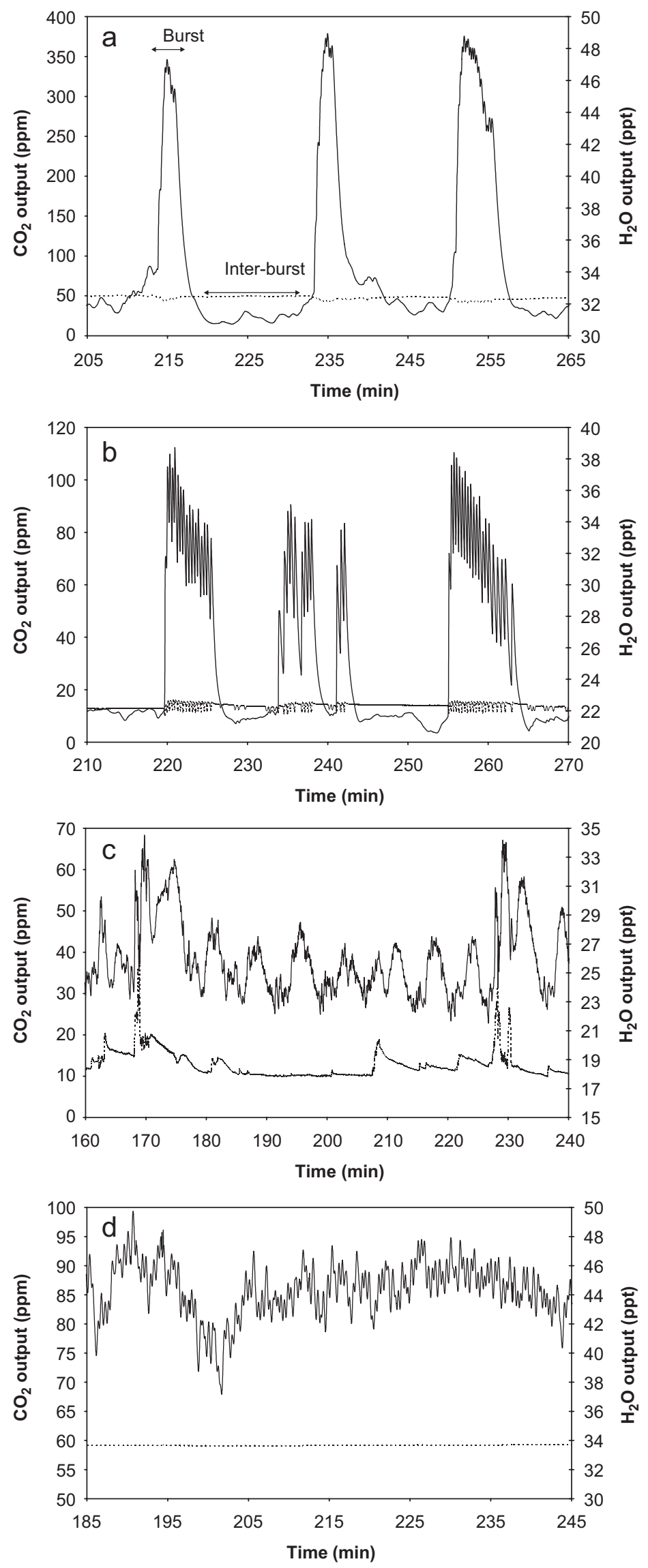

Fig. 1. Representative $1 \mathrm{~h}$ traces for M. rhinoceros showing $\mathrm{CO}_{2}$ output (solid line) and $\mathrm{H}_{2} \mathrm{O}$ output (dotted line) at (a) $21 \%$ oxygen, (b) $10 \%$ oxygen, (c) $2 \%$ oxygen during degraded CGE and (d) $2 \%$ oxygen during continuous gas exchange at $20{ }^{\circ} \mathrm{C}$. Note: trials at 2 and $10 \%$ oxygen were conducted at a higher flow rate $\left(350 \mathrm{~mL} \mathrm{~min}^{-1}\right)$ compared to the $21 \%$ oxygen trials $\left(200 \mathrm{~mL} \mathrm{~min}^{-1}\right)$ as described in Section 2. 
Table 1

The effect of oxygen concentration on the cyclic gas exchange in M. rhinoceros $(n=6)$ at $20^{\circ} \mathrm{C}$ (mean \pm S.D.)

\begin{tabular}{llll}
\hline Oxygen tension (\%) & 21 & 10 & 2 \\
\hline Mass (g) & $26.52 \pm 2.42$ & $26.2 \pm 1.97$ & $23.82 \pm 2.42$ \\
No. of CGE cycles examined & 26 & 30 & 11 \\
Water output during CGE $\left(\mathrm{mg} \mathrm{h}^{-1}\right)$ & $176.18 \pm 21.98$ & $197.48 \pm 78.91$ & $308.48 \pm 51.68$ \\
Total cycle $\mathrm{CO}_{2}$ output $\left(\mathrm{mL} \mathrm{h}^{-1}\right)$ & $0.887 \pm 0.242$ & $0.824 \pm 0.512$ & $0.935 \pm 0.196$ \\
Burst $\mathrm{CO}_{2}$ output $\left(\mathrm{mL} \mathrm{h}^{-1}\right)$ & $1.115 \pm 0.359$ & $1.179 \pm 0.789$ & - \\
Burst period $(\mathrm{min})$ & $5.9 \pm 0.6$ & $10.2 \pm 5.3^{*}$ & - \\
Burst frequency (bursts h & \\
Inter-burst $\mathrm{CO}_{2}$ output $\left(\mathrm{mL} \mathrm{h}^{-1}\right)$ & 3.9 & 3.0 & - \\
Inter-burst period (min) & $0.435 \pm 0.205$ & $9.247 \pm 0.122^{*}$ & - \\
CGE cycle period (min) & $10 \pm 3.5$ & $19 \pm 3.8 \pm 6.2$ & - \\
\hline
\end{tabular}

Phase specific data is not presented for the $2 \%$ oxygen treatment due to the rarity of CGE cycles and less defined phase interfaces.

*Indicates a significant difference between means at $21 \%$ and $10 \%$ oxygen (ANOVA, $p<0.05$ ).

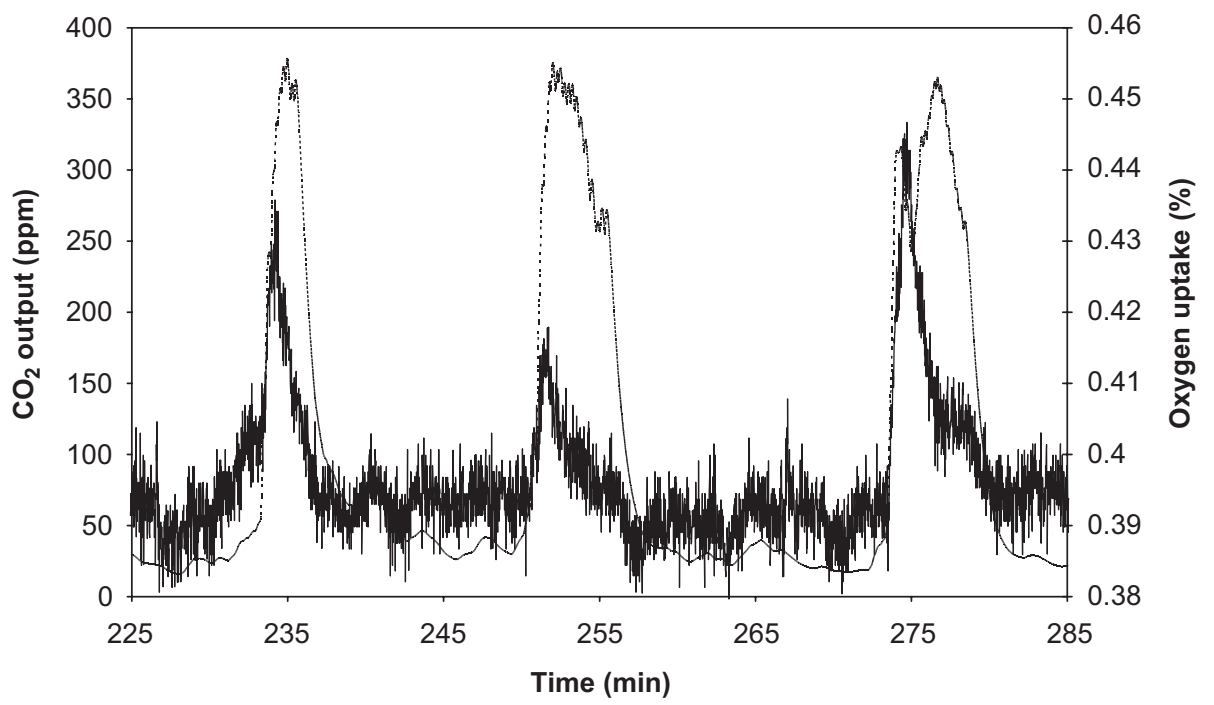

Fig. 2. A representative $1 \mathrm{~h}$ trace for M. rhinoceros showing simultaneous measurement of oxygen uptake (solid line) and $\mathrm{CO}_{2}$ output (dotted line) during $\mathrm{CGE}$ at normoxia and $20^{\circ} \mathrm{C}$. Oxygen uptake during a $\mathrm{CO}_{2}$ burst is clearly elevated over that during the inter-burst period.

Table 2

Total $\mathrm{CO}_{2}$ and water loss rates for M. rhinoceros $(n=6)$ when immobile at $21 \%$ oxygen relative to temperature (mean \pm S.D.)

\begin{tabular}{llrr}
\hline Temperature $\left({ }^{\circ} \mathrm{C}\right)$ & 10 & 20 & 30 \\
\hline Mass $(\mathrm{g})$ & $26.83 \pm 3.49$ & $26.52 \pm 2.42$ & $25.86 \pm 2.54$ \\
Water output $\left(\mathrm{mg} \mathrm{h}^{-1}\right)$ & $80.88 \pm 21.12^{\mathrm{c}}$ & $176.18 \pm 21.98^{\mathrm{b}}$ & $231.08 \pm 35.3^{\mathrm{a}}$ \\
Total $\mathrm{CO}_{2}$ output $\left(\mathrm{mL} \mathrm{h}^{-1}\right)$ & $0.418 \pm 0.361^{\mathrm{c}}$ & $0.887 \pm 0.242^{\mathrm{b}}$ & $1.711 \pm 0.537^{\mathrm{a}}$ \\
\hline
\end{tabular}

Means in a row with different letters are significantly different (ANOVA, $p<0.05$ ).

relatively short period of time. For example, the grasshopper, Taeniopoda eques (average mass $2.3 \mathrm{~g}$ ), features bursts of $5.4 \mathrm{~min}$ and an inter-burst period (combined closed and flutter phase) of $40.2 \mathrm{~min}$ (Harrison et al., 1995). Among other cockroaches, Periplaneta americana (average mass $1 \mathrm{~g}$ ), feature bursts of $11.5 \mathrm{~min}$ and an inter-burst period of 15.5 min (unpublished data, J.D.W. Kestler, 1985) suggesting that the frequency of bursts in $M$. rhinoceros is relatively high (Table 1).

Among other cockroaches, cyclic $\mathrm{O}_{2}$ consumption has been recorded from the tropical cockroach, Blaberus giganteus (Bartholomew and Lighton, 1985) and a number of different species exhibit DGE, e.g. the American cockroach (P. americana) (Kestler, 1985), Perisphaeria sp. 
(Marais and Chown, 2003), Blaberidae sp. (Marais et al., 2005 ) and the German cockroach (Blattella germanica) (Dingha et al., 2005). Discontinuous ventilation is therefore common among cockroaches despite variable life histories. Fig. 3 shows $\mathrm{CO}_{2}$ output rates relative to mass at $21 \%$ oxygen and $20^{\circ} \mathrm{C}$ for $M$. rhinoceros as well as B. germanica, $P$. americana and $B$. giganteus (a large, tropical cave dwelling species). Additionally, data from several other tracheate arthropods (two species of beetle, a pseudoscorpion and a centipede) that exhibit discontinuous ventilation patterns is presented. In a broader context, cockroaches have relatively high metabolic rates and whilst M. rhinoceros represents a marginally lower $\mathrm{CO}_{2}$ output rate for its mass among the cockroaches, it would not be classified as a low metabolic performer more generally.

Relatively few studies have investigated the effect of oxygen tension on CGE or DGE. Lighton and Garrigan (1995) investigated DGE in the ant, Camponotus vicinus, at oxygen tensions ranging between $21 \%$ and $8 \%$ and described how the inter-burst period lengthened as a result of a prolonged flutter phase. This was attributed to increased spiracular conductance required to meet tissue oxygen demand during hypoxia. Interestingly, diapausing lepidopteran pupae decreased the duration of the flutter phase at reduced oxygen tensions which has been attributed to convection (Schneidermann and Williams, 1955; Levy and Schneidermann, 1966; Snyder et al., 1995). For $M$. rhincoceros, total cycle $\mathrm{CO}_{2}$ output rates remained similar irrespective of oxygen tension and greater $\mathrm{CO}_{2}$ output during an extended inter-burst period was observed only as gas exchange became continuous at $2 \%$ oxygen (Fig. 1). This suggests that only when exposed to severe

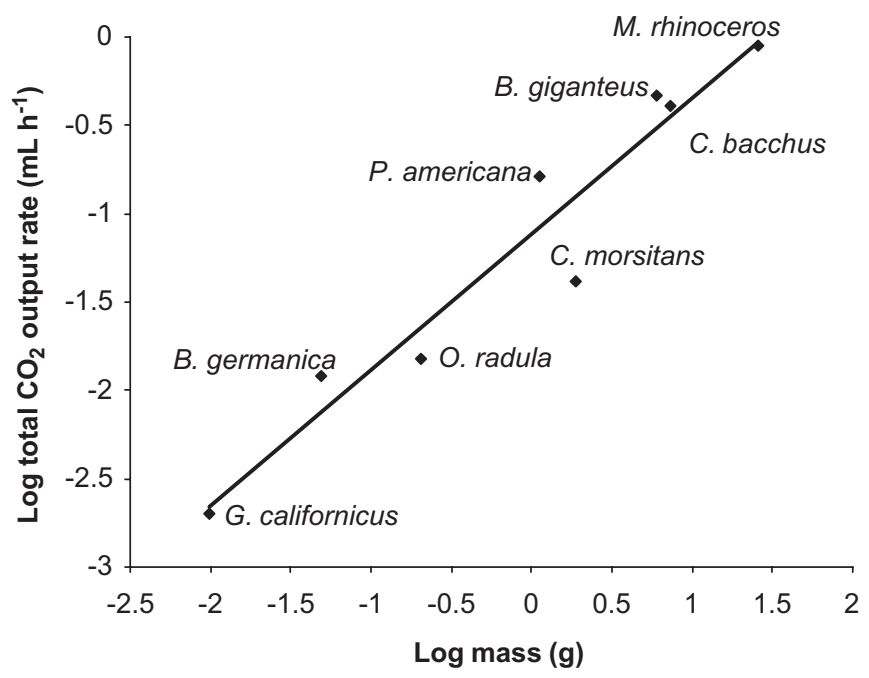

Fig. 3. Relationship between $\log$ mass and $\log$ total $\mathrm{CO}_{2}$ output rate for selected terrestrial tracheated arthropods that perform CGE or DGE (slope $=0.77$ ). Cockroaches: M. rhinoceros, $P$. americana (unpublished data, J.D.W), B. giganteus (Enger and Savalov, 1958), B. germanica (Dingha et al., 2005); Beetles: Circellium bacchus (Duncan and Byrne, 2000), Omorgus radula (Bosch et al., 2000); Pseudoscorpion: Garypus californicus (Lighton and Joos, 2002); Centipede: Cormocephalus morsitans (Klok et al., 2002). hypoxia must this species increase spiracular conductance beyond what can be supported by the typical CGE regime.

The transition from cyclic to continuous gas exchange in response to severe hypoxia was reflected by oxygen tension affecting the proportion of time an animal performed CGE during the trials. Temperature also affected the time spent performing CGE and resulted in a doubling of $\mathrm{CO}_{2}$ output with each increase of $10^{\circ} \mathrm{C}$. Whilst data at 10 and $30^{\circ} \mathrm{C}$ excludes periods of movement, phase specific analysis of CGE cycles, as has been presented for $20^{\circ} \mathrm{C}$ treatments, was not possible due to increased variability and fewer complete cycles.

A small number of trials at $21 \%$ oxygen and $20{ }^{\circ} \mathrm{C}$ showed oxygen uptake peaking concurrently with $\mathrm{CO}_{2}$ bursts (Fig. 2). Despite the inter-burst period remaining similar from $21 \%$ to $10 \%$ oxygen, the burst phase almost doubles (Table 1) and thus halving the oxygen concentration may result in lengthening of the burst phase to maintain oxygen uptake. Whilst Hetz and Bradley (2005) show oxygen uptake that approaches equilibrium with the atmosphere during the open phase from a pupa of Attacus atlas, oxygen uptake during the open phase has nonetheless been rarely discussed relative to oxygen uptake during spiracular fluttering (Lighton, 1996). For M. rhinoceros, an increase in burst phase duration based on maintaining oxygen uptake when exposed to moderate hypoxia seems entirely plausible, however further investigation is required.

Water loss rate during CGE was most strongly influenced by increasing temperature whereby a two-fold increase was observed from 10 to $20^{\circ} \mathrm{C}$ and a further $31 \%$ increase from 20 to $30^{\circ} \mathrm{C}$. Decreased oxygen tension from $21 \%$ also increased water loss rates presumably due to heightened ventilatory activity at $2 \%$ oxygen. Total water loss in $M$. rhinoceros is relatively high and in line with expectation given a mesic, soil burrowing life history. For example, compared with water loss rates reported for the tropical giant Madagascar hissing cockroach, Gromphadorhina portentosa, where individual adult males (average mass $6.355 \mathrm{~g}$ ) lost $0.098 \% \mathrm{~h}^{-1}$ body mass at $25^{\circ} \mathrm{C}$ in dry air (Yoder and Grojean, 1997), we observed $0.664 \% \mathrm{~h}^{-1}$ at $20{ }^{\circ} \mathrm{C}$ and $0.894 \% \mathrm{~h}^{-1}$ at $30^{\circ} \mathrm{C}$ for $M$. rhinoceros (calculated from values in Table 2). Whilst G. portentosa lives on the forest floor (not within a burrow) and experiences a long dry season favouring superior water retention (Yoder and Grojean, 1997), the comparison nonetheless demonstrates relatively high water loss in $M$. rhinoceros which spends most of its life underground.

The underground (chthonic) hypothesis postulated for DGE, has suggested that discontinuous ventilation plays a role in conferring tolerance to potentially stressful atmospheric conditions encountered in underground burrows (Lighton, 1998). This is at least partially supported for M. rhinoceros. Anderson and Ultsch (1987) reported that whilst uppermost soil layers are generally normoxic, even relatively shallow burrows can become moderately hypoxic due to respiration within confined space. Whilst we lack 
oxygen data from within the $M$. rhinoceros burrow, moderate hypoxia is considered likely at the base of the burrow. We observed CGE maintained at $10 \%$ oxygen with comparable total $\mathrm{CO}_{2}$ output to that at normoxia, but it was either affected or abandoned under severe hypoxia ( $2 \%$ oxygen). Future measurement of burrow oxygen concentrations is required to determine whether exposure to severe hypoxia is realistic, however our data indicate CGE is flexible in maintaining gas exchange with relatively little effect on water loss in moderately oxygen reduced atmospheres.

Discontinuous ventilation has also been proposed as a water conservation technique (termed the hygric hypothesis) whereby respiratory transpiration may be reduced whilst the spiracles are periodically closed (Hadley, 1994; Lighton, 1996). Whilst DGE has been shown to modulate respiratory water loss (Chown and Davis, 2003), the credibility of the hypothesis has nonetheless been questioned on the basis of respiratory water loss typically accounting for less than $20 \%$ of total water loss (Chown, 2002). Given that $\mathrm{CO}_{2}$ release was never observed to fall to near zero in our experiments and that therefore water loss during a $\mathrm{CO}_{2}$ burst was not significantly different from that during an inter-burst period at either $21 \%$ or $10 \%$ oxygen at $20^{\circ} \mathrm{C}$, we conclude that the hygric hypothesis is unable to explain CGE in M. rhinoceros.

\section{Conclusion}

CGE is the common respiratory pattern for M. rhinoceros during periods spent immobile. Compared with other CGE or DGE performing cockroach species at $20{ }^{\circ} \mathrm{C}, M$. rhinoceros has a slightly lower $\mathrm{CO}_{2}$ output rate relative to mass which is in line with expectation given a more sedentary, long-lived life history. At normoxia and moderate hypoxia, we have shown that CGE is maintained and that water loss during the inter-burst and burst periods is not significantly different. CGE is however limited under severe hypoxia when the pattern is degraded and total water loss increases. Although we lack field measurements from within $M$. rhinoceros burrows, it is reasonable to assume moderate hypoxia but only occasional transient periods of severe hypoxia during high rainfall and localised flooding (Baumgartl et al., 1994). CGE in this species would therefore appear to be the predominant mode of gas exchange during extended periods underground.

\section{Acknowledgements}

For technical assistance we thank Greg Dojchinov. This research was financially supported by a Ph.D. scholarship awarded to J.D.W. by the Bulk Handling Companies of Australia.

All experiments as part of the research presented herein were conducted in compliance with the current laws of Australia.

\section{References}

Anderson, J.F., Ultsch, G.R., 1987. Respiratory gas concentration in the microhabitats of some Florida arthropods. Comparative Biochemistry and Physiology 88, 585-588.

Bartholomew, G.A., Lighton, J.R.B., 1985. Ventilation and oxygen consumption during rest and locomotion in a tropical cockroach, Blaberus gigantus. Journal of Experimental Biology 118, 449-454.

Baumgartl, H., Kritzler, K., Zimelka, W., Zinkler, D., 1994. Local $\mathrm{pO}_{2}$ measurements in the environment of submerged soil microarthropods. Acta Oecologia 15, 781-789.

Bosch, M., Chown, S.L., Scholtz, C.H., 2000. Discontinuous gas exchange and water loss in the karatin beetle Omorgus radula: further evidence against the water conservation hypothesis? Physiological Entomology 25, 309-314.

Brown, W.V., Rose, H.A., Lacey, M.J., Wright, K., 2000. The cuticular hydrocarbons of the giant soil-burrowing cockroach Macropanesthia rhinoceros Saussure (Blattodea: Blaberidae: Geoscapheinae): analysis with respect to age, sex and location. Comparative Biochemistry and Physiology Part B 127, 261-277.

Chown, S.L., 2002. Respiratory water loss in insects. Comparative Biochemistry and Physiology Part A 133, 791-804.

Chown, S.L., Davis, A.L., 2003. Discontinuous gas exchange and the significance of respiratory water loss in scarabaeine beetles. Journal of Experimental Biology 206, 3547-3556.

Chown, S.L., Nicholson, S.W., 2004. Insect Physiological Ecology: Mechanisms and Patters. Oxford University Press Inc., New York.

Chown, S.L., Gibbs, A.G., Hetz, S.K., Klok, C.J., Lighton, J.R.B., Marais, E., 2006. Discontinuous gas exchange in insects: a clarification of hypotheses and approaches. Physiological and Biochemical Zoology 79 (2), 333-343.

Day, M.F., 1950. The histology of a very large insect, Macropanesthia rhinoceros Sauss. (Blattidae). Journal of Science Research B 3, 61-75.

Dingha, B.N., Appel, A.G., Eubanks, M.D., 2005. Discontinuous carbon dioxide release in the German cockroach, Blattella germanica (Dictyoptera: Blattellidae), and its effect on respiratory transpiration. Journal of Insect Physiology 51, 825-836.

Dudley, R., 1998. Atmospheric oxygen, giant palaeozoic insects and the evolution of aerial locomotor performance. Journal of Experimental Biology 201, 1043-1050.

Duncan, F.D., Byrne, M.J., 2000. Discontinuous gas exchange in dung beetles: patterns and ecological implications. Oecologia 122, 452-458.

Enger, P.S., Savalov, P., 1958. A note on the metabolism of a few giant, tropical, terrestrial arthropods. Journal of Insect Physiology 2, 232-233.

Graham, J.B., Dudley, R., Aguilar, N.M., Gans, C., 1995. Implications of the late Palaeozoic oxygen pulse for physiology and evolution. Nature $375,117-120$.

Gray, E.M., Bradley, T.J., 2006. Evidence from mosquitoes suggests that cyclic gas exchange and discontinuous gas exchange are two manifestations of a single respiratory pattern. Journal of Experimental Biology 209, 1603-1611.

Greenlee, K.J., Harrison, J.F., 2004. Development of respiratory function in the American locust Schistocerca americana I. Across-instar effects. Journal of Experimental Biology 207, 497-508.

Hadley, N.F., 1994. Water Relations of Terrestrial Arthropods. Academic Press Inc., San Diego, CA.

Harrison, J.F., Hadley, N.F., Quinlan, M.C., 1995. Acid-base status and spiracular control during discontinuous ventilation in grasshoppers. Journal of Experimental Biology 198, 1755-1763.

Hetz, S.K., Bradley, T.J., 2005. Insects breathe discontinuously to avoid oxygen toxicity. Nature 433, 516-519.

Hoback, W.W., Stanley, D.W., 2001. Insects in hypoxia. Journal of Insect Physiology 47, 533-542. 
Kestler, P., 1985. Respiration and respiratory water loss. In: Environmental Physiology and Biochemistry of Insects. Springer, Berlin.

Klok, C.J., Mercer, R.D., Chown, S.L., 2002. Discontinuous gas-exchange in centipedes and its convergent evolution in treacheated arthropods. Journal of Experimental Biology 205, 1019-1029.

Levy, R.I., Schneidermann, H.A., 1966. Discontinuous respiration in insects. II. The direct measurement and significance of changes in tracheal gas composition during the respiratory cycle of silkworm pupae. Journal of Insect Physiology 12, 83-104.

Lighton, J.R.B., 1996. Discontinuous gas exchange in insects. Annual Review of Entomology 41, 309-324.

Lighton, J.R.B., 1998. Notes from the underground: towards ultimate hypotheses of cyclic, discontinuous gas exchange in tracheate arthropods. American Zoologist 38, 483-491.

Lighton, J.R.B., Garrigan, D., 1995. Ant breathing: testing regulation and mechanism hypotheses with hypoxia. Journal of Experimental Biology 198, 1613-1620

Lighton, J.R.B., Joos, B., 2002. Discontinuous gas exchange in the Pseudoscorpion Garypus californicus is regulated by hypoxia, not hypercapnia. Physiological and Biochemical Zoology 75 (4), 345-349.
Marais, E., Chown, S.L., 2003. Repeatability of standard metabolic rate and gas exchange characteristics in a highly variable cockroach, Perisphaeria sp. Journal of Experimental Biology 206, 4565-4574.

Marais, E., Klok, C.J., Terblanche, J.S., Chown, S.L., 2005. Insect gas exchange patterns: a phylogenetic perspective. Journal of Experimental Biology 208, 4495-4507.

Reinhold, K., 1999. Energetically costly behaviour and the evolution of resting metabolic rate in insects. Functional Ecology 13, 217-224.

Rugg, D., Rose, H.A., 1991. Biology of Macropanesthia rhinoceros Saussure (Dictyoptera: Blaberidae). Annals of the Entomological Society of America 84 (6), 575-582.

Schneidermann, H.A., Williams, C.M., 1955. An experimental analysis of the discontinuous respiration of the Cecropia silkworm. Biological Bulletin 109, 123-143.

Slama, K., 1999. Active regulation of insect respiration. Physiology Biochemistry and Toxicology 92 (6), 916-929.

Snyder, G.K., Sheafor, B., Scholnick, D., Farrelly, C., 1995. Gas exchange in the insect tracheal system. Journal of Theoretical Biology 172 (3), 199-207.

Yoder, J.A., Grojean, N.C., 1997. Group influence on water conservation in the giant Madagascar hissing cockroach, Gromphadorhina portento$s a$ (Dictyoptera: Blaberidae). Physiological Entomology 22 (1), 79-82. 